\title{
Cyanoacrylate application on colonic anastomosis: is it safe or not?
}

\author{
Gürhan Güngör ${ }^{1}$, Gökhan Demiral', Metin Şenol ${ }^{3},{\text { Barış Bayraktar }{ }^{4}, Y^{2} \text { ahya Çelik }{ }^{5}, \text { Salih Bölük }}^{6}$ \\ ${ }^{1}$ General Surgery Clinic, Kadirli State Hospital, Osmaniye, Turkey \\ ${ }^{2}$ General Surgery Clinic, Rize State Hospital, Rize, Turkey \\ ${ }^{3}$ Private Adatip Hospital, Sakarya, Turkey \\ ${ }^{4}$ General Surgery Clinic, Private Uzmanlar Hospital, Yalova, Turkey \\ ${ }^{5}$ General Surgery Clinic, Gebze Fatih State Hospital, Kocaeli, Turkey \\ ${ }^{6}$ General Surgery Clinic, Çankırı State Hospital, Çankırı, Turkey
}

Key words: cyanoacrylate, anastomosis, colon.

Address for correspondence: Metin Şenol, Private Adatip Hospital, 54000 Sakarya, Turkey, phone: +90 5056407955 , e-mail: dr_metin@yahoo.com

\begin{abstract}
Introduction: Major complications of colonic anastomosis include fistula, bleeding, and anastomotic stricture, and the most common one is anastomotic leakage. Many organic or inorganic tissue adhesives are being used such as fibrin glue or cyanoacrylate to strengthen or protect colonic anastomosis. Up to now, a great number of studies have been carried out to investigate the effects of these biomaterials.

Aim: To determine the effect of cyanoacrylate application on anastomosis safety.

Material and methods: In this experimental study, rats were divided into two groups; a control group and an experimental group. Full-thickness incisions were done on the left colon of the rats, and then end-to-end anastomosis was performed by using 5/0 silk separated sutures. In the experimental group we applied cyanoacrylate over the sutures. The samples were taken on the $7^{\text {th }}$ day.

Results: In the control group the average tissue hydroxyproline levels and the average bursting pressures were significantly higher than in the experimental group.

Conclusions: The purpose of all the experimental studies is to prevent and reduce anastomotic complications. Despite all the studies that have been done, colonic anastomosis complications continue to be a problem. As a result, we suggest that cyanoacrylate has a negative effect on the healing process of colonic anastomosis.
\end{abstract}

\section{Introduction}

Although surgical anastomosis is not a difficult process, surgeons hesitate to perform anastomoses and they seek reasons that are considered right to make this decision. The reasons for this hesitation are major complication risks; fistula, bleeding, and stricture at the anastomotic line. The most significant among these is anastomosis leakage $[1,2]$. Malnutrition, diabetes, shock, immunosuppression, hypoalbuminaemia, and chronic disease are some of the systemic factors effecting wound healing. Additionally, intra-abdominal sepsis, foreign bodies, and inadequate bowel cleansing are local factors that have a negative effect on the healing process. Anastomosis technique is another factor that is as important as the others. Tight anastomosis, lack of blood supply to the end of the anastomotic line, the presence of a pathological situation at the anastomosis, distal obstruction of the lumen, and poor anastomotic technique have adverse effects on healing.

Many organic or inorganic tissue adhesives are being used, such as fibrin glue or cyanoacrylate, to strengthen or protect the colonic anastomosis. Up to now, a great number of studies have been carried out to research the effects of these biomaterials. The aims of the studies until today have been to prevent and decrease anastomotic complications. Despite the studies, intestinal anastomosis complications still continue and 
more than half of the postoperative deaths are caused by sepsis related to anastomosis leakage [2, 3]. While the risk of anastomosis leakage is $1 \%$ in the proximal small intestine, it may increase up to $16 \%$ beyond the transverse colon $[4,5]$.

\section{Aim}

Major complications of colonic anastomosis are fistula, bleeding, and anastomotic stricture, and the most common one is anastomotic leakage. Many organic or inorganic tissue adhesives are currently used, such as fibrin glue or cyanoacrylate, to strengthen or protect colonic anastomosis. Up to now, lots of studies have been carried out to research the effects of these biomaterials. The aim of this study was to determine the effect of cyanoacrylate application on anastomosis safety.

\section{Material and methods}

This research was conducted at the Haydarpasa Education And Research Hospital Experimental Research and Animal Laboratory in the year 2013, after obtaining the approval of THE Board of Test Animal Research Ethics. During the study, the rules of the Helsinki declaration regarding care and usage of laboratory animals were applied with utmost care. Twenty-four Wistar Albino female rats, each 10 weeks old, were separated into two groups of 12 rats each. In the control group, while keeping the left colon bleeding, end-to-end anastomosis was performed with single layer separated 5/0 silk after resecting the $0.5 \mathrm{~cm}$ colon segment.

The same anastomosis technique of the control group was performed on the experimental group, and tissue glue (cyanoacrylate) was applied all around the anastomosis. The animals were kept in metal cages at normal room temperature and humidity.

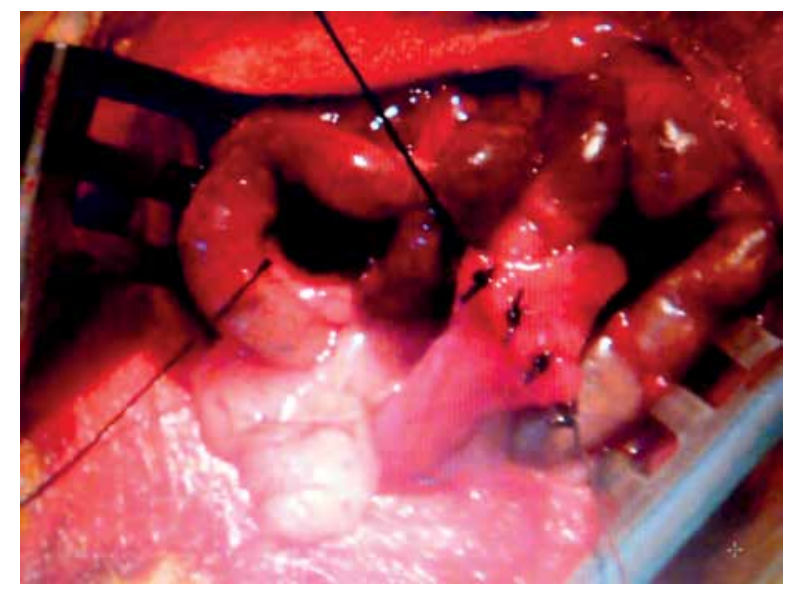

Figure 1. End-to-end anastomosis on the left colon
The experimental animals were left without food $12 \mathrm{~h}$ prior the operation. In the operation, $50 \mathrm{mg} / \mathrm{kg}$ ketamine sodium were administered intraperitoneally to obtain general anaesthesia. After shaving the operation site, antisepsis was ensured using povidone/iodine. Left colon was revealed via median laparotomy by keeping the left colon bleeding. End-to-end anastomosis was performed on the left colon by using one layer separated No: 5/0 silk (Figure 1). In the experimental group, cyanoacrylate was applied over the anastomosis and also $5 \mathrm{~mm}$ of the proximal and distal part of the anastomosis, which was performed with $5 / 0$ silk on the left colon (Figure 2).

Subsequently, the operation was ended by closing the abdomen. After the operations, the animals were placed into cages, three rats per cage. Standard rat food and water were given to all rats until the second operation. Rats in both groups were sacrificed by high dosage ether inhalation on the $7^{\text {th }}$ day postoperatively

\section{Anastomotic bursting pressure measurement}

Bursting pressures were recorded in $\mathrm{mm} \mathrm{Hg}$. Contents of anastomotic colons were carefully cleaned and colon ends were tied to the catheter using 3/0 silk again after closing the distal ends with a clamp and placing a polyethylene catheter $3 \mathrm{~mm}$ in diameter at the proximal ends. Catheters were tied to the setup and the pressure in the system was increased gradually after placing the colonic segments in a clear container filled with physiological saline solution.

While observing the anastomosis, when the first outlet of air from the anastomotic line or a nearby area was obtained, the pressure in the system was recorded as the bursting pressure. Subsequently, a 1-cm tissue covering the $0.5 \mathrm{~cm}$ distal and proximal of the anas-

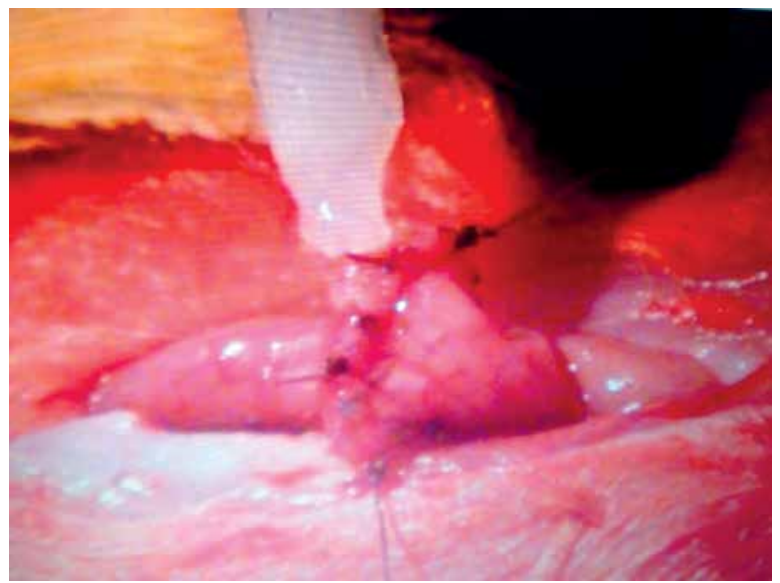

Figure 2. Cyanoacrylate was applied over the anastomosis 
tomosis line was resected and preserved at $-22^{\circ} \mathrm{C}$ to detect the hydroxyproline level in the tissue after fixing it in $1 \mathrm{cc}$ isotonic sodium chloride solution.

\section{Detection of hydroxyproline level}

Detection of the hydroxyproline level was performed by using the high performance liquid chromatography (HPLC) method. Materials were brought up to a normal ambient temperature prior to study. Materials obtained were extracted by treating with pure $\mathrm{HCl}$ at a temperature of $120^{\circ} \mathrm{C}$. The study material was obtained after centrifuging $30 \mathrm{~min}$ at a rate of $5000 \mathrm{rmp}$. An HPLC device (Shimadzu, Japan) was used in the study. Values were recorded. The study was concluded by applying the Student- $t$ test to the recorded values.

\section{Statistical analysis}

In the statistical analysis, NCSS 2007\&PASS 2008 Statistical Software (Utah, USA) was used to evaluate the data. The Student- $t$ test was used to compare the groups either in descriptive statistical methods (median, standard deviation) or quality values with normal range parameters. Value of $p<0.05$ was considered statistically significant.

\section{Results}

The hydroxyproline levels ranged from 168 to $621 \mu \mathrm{g} / \mathrm{g}$ tissue and the average value was $366.92 \pm 161.44$. The

Table I. Bursting pressures and tissue hydroxyproline levels $(n=24)$

\begin{tabular}{lcc} 
& Min-max $[\mathrm{mm} \mathrm{Hg}]$ & Mean \pm SD \\
\hline Hydroxyproline & $168-621$ & $366.92 \pm 161.44$ \\
\hline Bursting pressure & $90-260$ & $162.71 \pm 49.99$
\end{tabular}

Table II. Evaluation of the tissue hydroxyproline levels according to the groups

\begin{tabular}{|c|c|c|c|}
\hline \multirow[t]{2}{*}{ Groups } & \multicolumn{2}{|c|}{ Hydroxyproline } & \multirow[t]{2}{*}{$P$-value } \\
\hline & Mean & SD & \\
\hline Experimental & 228.17 & 39.31 & \multirow{2}{*}{$\begin{array}{c}0.001 \\
\text { (Student } t \text { test) }\end{array}$} \\
\hline Control & 505.67 & 104.62 & \\
\hline
\end{tabular}

Table III. Evaluation of the bursting pressure values according to the groups

\begin{tabular}{llcc} 
Groups & \multicolumn{2}{c}{ Bursting pressure } & P-value \\
\cline { 2 - 3 } & Mean & SD & \\
\hline Experimental & 136.25 & 31.63 & $\begin{array}{c}0.006 \\
\text { (Student } t \text { test) }\end{array}$ \\
\cline { 1 - 3 } Control & 189.17 & 51.95 &
\end{tabular}

bursting pressure values ranged from 90 to $260 \mathrm{~mm} \mathrm{Hg}$ and the average value was $162.71 \pm 49.99 \mathrm{~mm} \mathrm{Hg}$ (Table I).

Significant statistical differences were detected among the tissue hydroxyproline levels in two groups $(p<0.01)$; the average tissue hydroxyproline level in the control group was significantly higher than in the experimental group (Table II).

Significant statistical differences were detected among the average bursting pressures in the two groups ( $p<0.01$ ); the average bursting pressure in the control group was significantly higher than in the experimental group (Table III).

\section{Discussion}

Wound healing is a complex biological process that continues with cell division, chemotaxis, neovascularisation, extracellular matrix protein synthesis, and scar formation [6]. More homogeneous tissues such as skin rarely encountered serious problems in wound healing. On the other hand, the healing process is under the influence of the negative effect of colon microorganisms on heterogeneous tissues such as colon.

Intestinal anastomosis becomes necessary in many intestinal pathologies especially in malignant colon tumours. Morbidity and mortality rates of colonic anastomosis leakage are higher than others [7]. Malnutrition, diabetes, shock, immunosuppression, hypoalbuminaemia, and chronic disease are some of the systemic factors effecting wound healing. Additionally, intra-abdominal sepsis, foreign bodies, and inadequate bowel cleansing are local factors that have a negative effect on the healing process. Anastomosis technique is another factor, which is as important as the others. Tight anastomosis, lack of blood supply to the end of anastomotic line, the presence of a pathological situation at the anastomosis, distal obstruction of the lumen, and poor anastomotic technique have adverse effects on healing.

The number of microorganisms in the colon lumen is greater than the other side of the gastrointestinal tract. For this reason anastomotic leakage of the colon is observed much more than of the stomach and small intestine $[8,9]$. The distal segment of the left hemi-colon in particular has higher risk of anastomosis leakage and impairment [10-13]. These complications lead to high morbidity and mortality $[11,14,15]$. Due to all of these, studies of intestinal anastomoses have concentrated mostly on the colon. For this reason, in our study we preferred to practice the effects of a cyanoacrylate agent in the descending colon anastomosis, which is the most problematic segment.

Tissue adhesives are in two groups: synthetic tissue adhesives (cyanoacrylate derivatives, hydrogel) 
and biological tissue adhesives (fibrin glue, photodynamic fibrin glue) [16, 17]. There are various types of cyanoacrylate derivatives; N-heptyl, isobutyl (Histacryl), methyl-2 (Eastman 910), carbohexoxy methyl-2, N-butyl (Nexacryl, USA), isobutyl-2, N-butyl-2 (Histoacryl-N-Blue, Adhist), 2-isobutyl, octyl, and 2-octyl [16, 18]. In this study octyl cyanoacrylate was preferred.

The tissue adhesive effect of the cyanoacrylate was firstly discovered by Eastman Kodak Company in 1951 and extensive researches have begun $[19,20]$. Cyanoacrylate adhesives have been used for many years in the fields of medicine such as ophthalmology, dentistry, pediatric surgery, general surgery and cardiovascular surgery [21-24]. Octyl cyanoacrylate was approved by the American Food and Drug Administration (FDA) as a tissue adhesive in skin lacerations [21].

Various organic (such as fibrin adhesive) and inorganic tissue adhesives (cyanoacrylate derivatives) are being investigated for their ease of application, adhesiveness, elasticity, features of absorption or degradation, haemostasis effect, wound healing acceleration, impact as a foreign body, and risk of infection [25]. Bactericidal and bacteriostatic effects with cyanoacrylate derivatives were determined in the applied area by avoiding the development of infection. Negligible slight submucosal inflammation has been reported in the applied area when compared to other synthetic substances [26].

In a study on rats Madden et al. described that explaining the importance of the collagen amount in biology of wound healing is not enough. The rates of collagen synthesis and lysis should also be known. They claimed that the collagen synthesis and deposition may be detected by giving marked proline in a certain period of time and measuring the hydroxyproline amount in a healing wound [27].

Croinin reported in a study that in measurements of anastomotic bursting pressure, the force being applied gradually increases after the third post-anastomosis day and reaches a maximum on the $7-10^{\text {th }}$ day. It was also reported that on the first 3 days hydroxyproline levels decrease by $40 \%$ at the anastomosis site, return to the normal level after the $5^{\text {th }}$ day, and increase above the normal level on the $10-14^{\text {th }}$ days [28]. In our study we aimed to investigate the influence of cyanoacrylate material on anastomosis. For this purpose, anastomot ic bursting pressures and tissue hydroxyproline levels were measured on the $7^{\text {th }}$ postoperative day.

In an experimental colonic anastomosis study with cyanoacrylate, Yıldız et al. divided 40 Wistar albino rats into two main groups. In the $1^{\text {st }}$ group (20 rats) colonic resection and polypropylene sutures were applied. Ten rats (group 1a) were sacrificed on the $3^{\text {rd }}$ postoperative day and other 10 (group $1 \mathrm{~b}$ ) were sacrificed on the $7^{\text {th }}$ day for the investigation of the anastomosis. In the $2^{\text {nd }}$ group colonic resection and polypropylene sutures were applied with cyanoacrylate. Ten rats (group 2a) were sacrificed postoperatively on the $3^{\text {rd }}$ day and others (group $2 \mathrm{~b}$ ) on the $7^{\text {th }}$ day. Anastomotic bursting pressure rates, tissue hydroxyproline levels, and intensity of fibrosis on the anastomosis site were measured for the evaluation of the anastomosis. Anastomotic bursting pressures in group $2 \mathrm{a}$ were significantly higher than in group $1 \mathrm{a}$ $(p<0.05)$. There was no significant difference between group $1 b$ and $2 b$. There were no significant differences between groups regarding tissue hydroxyproline levels and collagen density at the anastomosis line [29].

Kanelos et al. investigated the adhesion score and anastomotic bursting pressure rates of 20 rats. On the control group 6/0 polypropylene sutures were applied. 2-octyl cyanoacrylate was additionally applied in the study group. The group were sacrificed postoperatively on the $7^{\text {th }}$ day and no significant difference was reported [30].

Irkorucu et al. experimentally studied with 40 Wistar albino rats. $6 / 0$ polypropylene suture was applied with 2-octyl cyanoacrylate on the left colon, and no significant difference was reported postoperatively on the $4^{\text {th }}$ day for both tissue hydroxyproline levels and anastomotic bursting pressures between groups [31].

In another study of Nursal et al. 90 Wistar albino rats were grouped. Octyl cyanoacrylate was applied on anastomosis and rats were sacrificed postoperatively on the $3^{\text {rd }}$ and $7^{\text {th }}$ days. Bursting pressures, tissue hydroxyproline levels, and histopathological examinations were obtained. There was no significant difference between groups on the $3^{\text {rd }}$ postoperative day. Bursting pressures on the $7^{\text {th }}$ day were seen to be lower in the octyl cyanoacrylate applied group. In this group tissue necrosis, peritonitis, and exudative reactions were observed. It was reported in this study that octyl cyanoacrylate provides no benefit to the anastomosis line, it increases the inflammation, and has a harmful effect on wound healing [32].

Our study was performed on 24 Wistar albino rats in two groups. The blood supply of the left colon was preserved. End-to-end anastomosis with 5/0 silk suture was applied to the control group. Other group was also supported roundly with cyanoacrylate $5 \mathrm{~mm}$ distal and proximal to the anastomosis. Groups were postoperatively sacrificed on the $7^{\text {th }}$ day. On the experimental group, the delay in wound healing was investigated. Also there was no environmental adipose tissue and omental migration on the specimen of experimental group. Bursting pressures and tissue hydroxyproline levels were also lower than in the control group.

There is no beneficial effect of cyanoacrylate on the experimental studies in the literature. In this study we 
also obtained negative findings of the effect of cyanoacrylate on the wound healing process of colonic anastomosis, similarly to the literature.

\section{Conclusions}

Major complications of colon anastomosis include fistula, bleeding, and anastomotic stricture. Anastomotic leakage is the most significant of these. The purpose of many experimental studies is to prevent and reduce anastomotic complications. Despite all of thte studies that have been carried out, bowel anastomosis complications continue to be a problem. As a result, we suggest that cyanoacrylate has a negative effect on the healing process of colonic anastomosis.

\section{Conflict of interest}

The authors declare no conflict of interest.

\section{References}

1. Jex RK, Van Heerden JA, Wolff BG, et al. Gastrointestinal anastomoses. Factors affecting early complications. Ann Surg 1987; 206: 138-41.

2. Hansen O, Schwenk W, Hucke HP, Stock W. Colorectal stapled anastomoses. Experiences and results. Dis Colon Rectum 1996; 39: 30-6.

3. Beard JD, Nicholson ML, Sayers RD, et al. Intraoperative air testing of colorectal anastomoses: a prospective, randomized trial. Br J Surg 1990; 77: 1095-7.

4. Nicholson ML, Beard JD, Horrocks M. Intra-operative inflow resistance measurement: a predictor of steal syndromes following femoro-femoral bypass grafting. Br J Surg 1988; 75 : 1064-6.

5. Vignali A, Fazio VW, Lavery IC, et al. Factors associated with the occurrence of leaks in stapled rectal anastomoses: a review of 1014 patients. J Am Coll Surg 1997; 185: 105-13.

6. Gregory LB, Lillion BN, Joseph GAB, et al. Enhancement of wound healing by topical treatment with epidermal growth factor. N Engl J Med 1989; 321: 776-9.

7. Thornton FJ, Barbul A. Healing in the gastrointestinal tract. Surg Clin North Am 1997; 77: 549-73.

8. Choti MA. Obstruction of large bowel. In: Current surgical therapy. Cameron JL (ed). Mosby-Year Book, $5^{\text {th }}$ ed. St. Louis, Philadelphia 1995; 162.

9. Williams NS. Large bowel obstruction. In: Surgery of the anus, rectum and colon. Keighley MRB (ed.). $3^{\text {rd }}$ ed. WB Saunders Company Ltd, London 1993; 1823.

10. Dunphy JE. The cut gut. Am J Surg 1970; 119: 1-8.

11. Goligher JC, Graham NG, de Dambal FT. Anastomotic dehiscence after anterior resection of rectum and sigmoid. Br J Surg 1970; 57: 109-18.

12. Morgenstern L, Yamakawa T, Shoshan BM, Lippman H. Anastomotic leakage after low colonic anastomoses. Am J Surg 1972; 123: 104-9.

13. Rousseldt LM, Slottery JR, Immediate complications of surgery of the large intestine. Surg Clin North Am 1964; 44: 397-9.
14. Dunphy JE. Preoperative preparation of the colon and other factors anastomotic healing. Cancer 1971; 28: 181-2.

15. Schrock TR, Deveney CW, Dunphy JE. Factors contributing to leakage of colonic anastomoses. Ann Surg 1973; 177: 513-8.

16. Sharma A, Kaur R, Kumar S, et al. Fibrin glue versus N-butyl-2-cyanoacrylate in corneal perforations. Ophthalmology 2003; 110: 291-8.

17. Khadem J, Truong T, Ernest JT. Photodynamic biologic tissue glue. Cornea 1994; 13: 406-10.

18. Webster RG Jr, Slansky HH, Refojo MF, et al. The use of adhesive for the closure of corneal perforations. Arch Ophthalmol 1968; 80: 625-6.

19. Barthelemy C, Audigier JC, Fraisse H. A non-tumoral esophagobronchial fistula managed by isobutyl-2-cyanoacrylate. Endoscopy $1983 ; 15: 357-8$

20. Glass BA, Albert HM. Suturless bronchial stump closure in an experimental study. J Thorac Cardiovasc Surg 1979; 49: 194-7.

21. Singer AJ, Quinn JV, Clark RE, Hollander JE. Closure of lacerations and incisions with octylcyanoacrylate: a multicenter randomized controlled trial. Surgery 2002; 131: 270-6.

22. Eiferman RA, Snyder JW. Antibacterial effect of cyanoacrylate glue. Arch Ophthalmol 1983; 101: 958-60.

23. Blum GN, Nolte NA, Robertson P. In vitro determination of the antimicrobial properties of two cyanoacrylate preparations. J Dent Res 1975; 54: 500-3.

24. Bruns TB, Robinson BS, Smith RJ, et al. A new tissue adhesive for laceration repair in children. J Pediatr 1998; 132: 1067-70.

25. Redl H, Schlag G. Properties of different tissue sealants with special emphasis on fibrinogen-based preparations. In: Fibrin sealant in operative medicine traumatology and orthopaedics. Schlag G, Redl H (eds.). $7^{\text {th }}$ ed. Springer-Verlag Berlin, Heidelberg 1986; 27-38.

26. Toriumu DM, Raslan WF, Freidman M, Tardy ME. Histotoxicity of cyanoacrylate tissue adhesives: a comparative study. Arch Otolaryngeal Head Neck Surg 1990; 11: 546-7.

27. Madden W, Peacock EF. Studies on the biology of collagen during wound healing. Role of the collagen synthesis and deposition in cutaneous wounds of the rat. Surgery 1968; 64: 288-94.

28. Croinin K, Jackson DS, Dunphy JE. Specific activity of hidroxyproline tritium in the healing colon. Surg Gyn Obst 1968; 1260: 1061-5.

29. Yıldız M, Demirbaş S, Akın ML. Cyanoacrylate application over the colonic anastomosis. Çağdaş Cerrahi Derg 2002; 16: 208-12.

30. Kanelos I, Mantzoros I, Demetriades H, et al. Sutureless colonic anastomosis in the rat: a randomized controlled study. Tech Coloproctol 2002; 6: 143-6.

31. Irkorucu O, Ucan BH, Çakmak GK, et al. Effect of 2-octyl cyanoacrylate on ischemic anastomosis of the left colon. J Invest Surg 2009; 22: 188-94.

32. Nursal TZ, Anarat R, Bircan S, et al. The effect of tissue adhesive, octyl-cyanoacrylate, on the healing of experimental high-risk and normal colonic anastomoses. Am J Surg 2004; 187: 28-32

Received: 5.05.2015

Accepted: 14.06 .2015 